\title{
Avaliação e Qualidade na Educação Superior: tendências na literatura e algumas implicações para o sistema de avaliação brasileiro
}

\author{
MARCO GUILHERME BRAVO BURLAMAQUI \\ Pesquisador e Docente da Universidade de Brasília - UnB \\ marco@cead.unb.br
}

\begin{abstract}
Resumo
O artigo pretende analisar as tendências acerca da discussão teórica que trata da avaliação/qualidade no ensino superior. Para tanto, abordamos quatro principais enfoques tratados na literatura: a perspectiva conceitual sobre a qualidade, a avaliação de sistemas, a avaliação institucional e os indicadores. A partir disso, pontuamos algumas considerações a respeito do atual sistema de avaliação para o ensino superior brasileiro.

Palavras-chave: avaliação, qualidade, educação superior, políticas públicas.
\end{abstract}

\section{Resumen}

El artículo tiene como objetivo analizar las tendencias acerca de la discusión teórica centrada en evaluación/calidad en la enseñanza superior. Para esto abordamos cuatro enfoques principales tratados en la literatura: la perspectiva conceptual sobre la calidad, la evaluación de sistemas, la evaluación institucional y los indicadores. Tomando esto como punto de partida señalamos algunas consideraciones respecto del sistema actual de evaluación para la enseñanza superior brasileña.

Palabras clave: evaluación, calidad, educación superior, políticas públicas.

\begin{abstract}
This article analyzes trends in the evaluation/quality debate in higher education. Four main approaches are discussed in the literature: a conceptual perspective on quality; systems evaluation; institutional evaluation and performance indicators. Finally, some considerations are advanced in relation to the present Brazilian higher education system of evaluation.

Key words: evaluation, quality, higher education, public policies.
\end{abstract}




\section{INTRODUÇÃO}

O objetivo principal deste artigo é analisar parte da discussão teórica que trata da qualidade/avaliação no ensino superior. Nele, abrangemos alguns dos principais autores que, recentemente, têm discutido essa temática. Assim, percebemos e sistematizamos as tendências de abordagem sobre o tema, o que, consideramos, agrega à discussão por permitir uma visão mais orgânica.

Notamos que o debate a respeito da avaliação e da qualidade na educação superior segue algumas linhas diferenciadas. A revisão da literatura permitiu sistematizar quatro enfoques principais: o primeiro abrange a perspectiva conceitual sobre a qualidade; o segundo, a discussão focada na avaliação de sistemas; o terceiro, na avaliação institucional; o quarto, nos indicadores. A organização proposta possibilita a análise contextualizada de sistemas de avaliação, como o brasileiro, em suas possibilidades e limitações.

Alguns autores debatem a temática da avaliação e/ou da qualidade no ensino superior discorrendo sobre aspectos relativos a um ou mais dos enfoques aqui tratados. Assim, é possível encontrar autores que, por exemplo, abordam a qualidade de maneira conceitual e que discutem e/ou propõem modelos de avaliação de sistemas.

Cabe explicar que a literatura específica a respeito da avaliação dos cursos de graduação é limitada, e o debate, nesse sentido, encontra-se basicamente diluído nas discussões sobre avaliação institucional e de sistemas, motivo pelo qual não trataremos a questão em tópico próprio. No âmbito dos cursos de graduação, há algumas discussões a respeito do extinto Exame Nacional de Cursos - ENC e do atual Exame Nacional de Desempenho dos Estudantes - Enade. Contudo, tais exames, isoladamente, não podem ser caracterizados como modelos de avaliação de cursos, pois representam apenas uma informação sobre conhecimentos e habilidades adquiridos por alunos concluintes. Os exames serão tratados no subitem "Discussão sobre os indicadores".

\section{A PERSPECTIVA CONCEITUAL SOBRE A QUALIDADE}

A pesquisa permitiu levantar alguns eixos e dicotomias que ajudam a compreender a questão de modo sistematizado. Essa sistematização talvez seja uma das principais contribuições deste trabalho, que permitirá, até mesmo, traçar algumas características da avaliação de sistemas e da avaliação institucional com base nas discussões presentes na literatura 
relativa a cada um desses processos. Assim, no debate conceitual sobre a qualidade destacam-se as noções de complexidade e de multidimensionalidade, além das seguintes dicotomias: qualidade a partir dos enfoques qualitativo/quantitativo e de produtos/processos. Por fim, observa-se na discussão uma linha que trata da eficácia e eficiência.

\subsection{Qualidade: um conceito complexo e multidimensional}

Avaliação e qualidade são dois termos intrinsecamente relacionados quando utilizados na educação. Como Silva (2001) argumenta, a qualidade é o foco central da avaliação, porque qualquer processo avaliativo visa a conhecer a qualidade ou, ao menos, seus indicadores; porém, segundo a autora, a definição conceitual desse termo é complexa.

Ferrer (1999) propõe-se a discutir o conceito de qualidade na educação, argumentando, inicialmente, que polissemia, indefinição e ambigüidade são características do termo "qualidade", quando aplicado a essa área. Desse modo, tem significados diferentes para distintos observadores e grupos de interesse, de maneira que há percepções divergentes acerca do que deveria ser mudado, em termos de garantia da qualidade.

Segundo esse autor, quando se fala de qualidade da educação, estáse falando de uma realidade complexa, como um sistema, uma instituição ou curso. Para ele, deve-se reconhecer expressamente a multidimensionalidade do conceito quando aplicado à área educacional, pois, quando falamos da qualidade de um curso ou de uma universidade estamos nos referindo não só a um aspecto, mas a várias dimensões desses contextos. Em uma universidade há, por exemplo, a dimensão da gestão, do corpo docente, do desempenho dos alunos, da pesquisa, da extensão, da estrutura física, entre outras.

Cunha e Wertheim (2001), fazendo menção ao texto que trata das implicações da "Declaração Mundial de Paris" para a política do ensino superior brasileiro, destacam que a qualidade da educação superior é um conceito multidimensional que inclui todas as funções e atividades: ensino, pesquisa, fomento à ciência, pessoal docente, estudantes, estruturas físicas, equipamentos, serviços de extensão à comunidade e o ambiente acadêmico em geral.

Nota-se, portanto, que falar da qualidade de uma instituição ou curso implica, nessa perspectiva, a noção da complexidade estrutural e da multidimensionalidade, no que tange a esses contextos. Essa noção pode representar o cuidado quanto à utilização do termo "qualidade 
institucional" de modo reducionista, tomando, por exemplo, apenas um aspecto ou dimensão de um contexto como representativo do todo.

\subsection{A dicotomia qualitativo/quantitativo na discussão sobre a qualidade do ensino superior}

A noção de complexidade de certa realidade a ser avaliada, como um curso ou uma instituição, permitiu notar que utilizar apenas informações ou métodos de natureza específica (quantitativa, por exemplo) pode representar a perda de informações importantes de ordem mais subjetiva ou qualitativa acerca desses contextos. Essa noção remete à utilização de componentes quantitativos e também qualitativos na avaliação, para uma visão integrada, uma vez que a própria realidade avaliada é composta por tais elementos, com informações de ambas as naturezas passíveis de serem levantadas. Contudo, é possível notar na literatura alguns posicionamentos reducionistas sobre a questão, ora enfatizando determinados aspectos, ora criticando.

Para Coêlho (2003), a utilização excessiva de informações quantitativas como base da avaliação do ensino superior, além de pressionar os indivíduos para que alcancem determinados indicadores quantitativos, relativos, por exemplo, ao número de pesquisas e publicações, não é capaz de garantir que se avalie a qualidade do trabalho realizado. Para ele, deve-se utilizar metodologias de avaliação que abarquem aspectos qualitativos ou subjetivos.

Sobrinho (2000), por outro lado, defende que as informações quantitativas e qualitativas sejam utilizadas de modo integrado na avaliação, pois cada tipo de informação se refere a aspectos e dimensões diferenciados acerca da realidade avaliada. Nesse sentido, o autor afirma:

Em muitos momentos do processo, a imbricação e combinação de perspectivas são altamente desejáveis e até mesmo necessárias. Há casos em que a objetividade quantitativa ou descritiva é imprescindível. Por exemplo, quando necessário isolar alguns aspectos do contexto para melhor e mais detalhadamente analisá-los. Importante é que isso não impeça a visão integrada e organizada do conjunto. (p. 80)

Informações de natureza quantitativa, como índices de qualificação do corpo docente, número de recursos por aluno e número de alunos por professor, podem ser relevantes, até mesmo se cruzadas com outras informações (quando poderão demonstrar, por exemplo, a sua contribuição para o alcance de objetivos). Contudo, há outros aspectos que talvez sejam 
importantes, e que informações quantitativas podem não dar conta de revelar, como a percepção subjetiva dos atores sobre o processo do qual fazem parte, o clima institucional, a motivação, o compromisso dos atores envolvidos, entre outros.

Naturalmente, informações subjetivas sugerem análises mais trabalhosas; entretanto, é possível levantar e sistematizar essas informações de modo mais objetivo. Nesse sentido, a percepção dos atores a respeito do processo poderia fomentar índices, por exemplo, quanto à satisfação acadêmica em relação aos cursos (há a possibilidade de agregar informações de vários atores, o que resulta em um índice que reflete a percepção geral). Assim, a informação subjetiva pode-se transformar em um indicador quantitativo.

\subsection{A dicotomia produtos/processos na discussão sobre a qualidade do ensino superior}

A literatura também revela a valorização ora de produtos, ora de processos, no que diz respeito à avaliação do ensino superior.

Tal qual encontramos, "produtos" dizem respeito ao que é alcançado ao final de determinados processos. Assim, "processos" se referem aos meios para se alcançar determinado produto. No âmbito educacional, nota-se que o ensino corresponde a um processo que sofre a interferência de vários aspectos ou variáveis. Por exemplo: uma fraca infraestrutura, um corpo docente mal qualificado, um sistema de acompanhamento deficiente e a falta de comprometimento dos atores envolvidos podem representar interferências negativas relativas ao processo de ensino. Assim, ao término desse processo, possivelmente o aluno terá uma formação precária, com conhecimentos e habilidades que não atendem às suas necessidades, ou seja, o resultado será negativo. A esse resultado, justamente, alguns autores como Sobrinho (2000), Morosini (1997), Leite e Morosini (1997), Coêlho (2003) e Schwartzman (1996) dão o nome de produto, podendo, no âmbito da avaliação, ser levantado não só no momento final de um processo educativo, mas também no subseqüente. Nesse sentido, são comuns pesquisas com formandos, com egressos e a utilização de exames que verifiquem os conhecimentos e as habilidades adquiridos por alunos concluintes.

Alguns autores criticam a visão de avaliação que valoriza apenas os produtos educativos, sobretudo a partir da implementação do ENC que visava, a princípio, avaliar resultados educativos e surgia como o único instrumento de avaliação do ensino de graduação. Segundo Sobrinho (2000), 
...importam aí, sobretudo, os produtos, na verdade aqueles que foram previamente escolhidos como padrão de qualidade, independentemente dos processos que os produziram, dos contextos que thes dão significação mais completa, das condições diferenciadas que os engendraram. (p. 162)

Na mesma linha, para Morosini (1997) a avaliação não pode ser única e exclusivamente de produto - de desempenho. Ela deve considerar o processo, ou seja, as condições que fizeram com que tal produto fosse obtido (p. 151).

Sem levar em conta os possíveis estigmas gerados com a utilização desses termos à época da implementação do Exame Nacional de Cursos, nota-se que o ensino corresponde a um processo permeado por vários aspectos ou variáveis que, ao final, trará algum resultado (produto). Nesse sentido, em uma perspectiva que compreende a complexidade e a multidimensionalidade inerentes às realidades avaliadas, ambas as dimensões fazem parte da avaliação.

\subsection{Eficácia e eficiência na discussão conceitual sobre qualidade}

Além da ênfase, ou crítica, acerca de aspectos ora quantitativos, ora qualitativos, assim como de produtos e processos, evidencia-se, na literatura sobre avaliação/qualidade no ensino superior, a tendência do enfoque a respeito da eficácia e eficiência na discussão conceitual sobre qualidade. Desse modo, o pressuposto básico é que uma instituição de qualidade deve ser eficiente e eficaz. Isso é notado, sobretudo, quando modelos de avaliação e sistemas de indicadores são propostos, como nos trabalhos de Estrada (1999), Schwartzman (1996 e 1997), Lapa e Neiva (1996) e Boclin (1999), entre outros.

Cohen e Franco (1993), ao tratarem de projetos sociais, expressam que a eficácia diz respeito ao grau em que determinados objetivos e metas são alcançados. Ferrer (1999), aplicando o conceito à área educacional, concorda com tal definição, conceituando-a como o grau de cumprimento efetivo dos objetivos educativos propostos. Segundo o autor, esses objetivos têm sido compreendidos em termos de resultados de alunos, mensurados por meio de testes ou de qualificações atribuídas pelos professores. Assim, essa concepção enfatizou o produto educativo. Para Ferrer (1999), trata-se de uma aproximação ao mercado produtivo, que considera a perfeição do produto como critério central da qualidade. Estrada (1999) também se enquadra nesse enfoque. Segundo ele, a dimensão da eficácia diz respeito ao alcance dos objetivos e propósitos estabelecidos. Dessa forma, uma instituição será de qualidade se seus estudantes e egressos demonstrarem os níveis de aprendizagem de conteúdos, habilidades, atitudes e valores 
propostos. Para Ferrer (1999), essa concepção apresenta alguns problemas, como a falta de reflexão sobre a pertinência do que é medido e, eventualmente, de objetivos claros e consensuados, o que às vezes implicam decisões unilaterais e a não-consideração de processos educativos que influenciam nos resultados.

A qualidade da educação também é vista pelo enfoque da eficiência. Isso aparece, principalmente, quando se propõem sistemas de indicadores para o ensino superior. Segundo Ferrer (1999), eficiência diz respeito ao grau de adequação entre os resultados obtidos e os recursos utilizados. Para o autor, o desenvolvimento de estatísticas de recursos humanos e econômicos, tais como a relação professor/aluno, taxas de egressos e de evasão, relacionadas ao gasto em educação por aluno e outras, referem-se a essa concepção de qualidade. Nessa perspectiva, um curso é de qualidade se utiliza adequadamente seus recursos, sem desperdícios. O problema dessa tendência, de acordo com Ferrer (1999), está relacionado a deixar de lado os processos complexos que ocorrem em instituições educacionais.

Quanto a essa dimensão, Estrada (1999) afirma que uma instituição será eficiente se seus recursos e processos forem utilizados apropriadamente e cumprirem sua função. Desse modo, há a preocupação com o uso adequado dos recursos e o desenvolvimento dos processos ante os resultados alcançados.

Pode-se inferir que a eficiência corresponde a uma dimensão relativa eminentemente à gestão. Como exemplo, nota-se que dois cursos diferenciados podem alcançar os mesmos objetivos; no entanto, um deles despende muito mais recursos do que o outro, sendo, por isso, considerado ineficiente.

Observa-se, também, que a dicotomia processos/produtos encontrase subjacente à discussão sobre qualidade, com enfoque na eficácia e na eficiência. A primeira pressupõe o alcance de objetivos educativos que podem ser caracterizados, em certo sentido, como produtos ou resultados. Por sua vez, a perspectiva da eficiência presume a análise de determinados processos, em sua relação com o alcance de determinados objetivos.

\section{QUALIDADE/AVALIAÇÃO NA PERSPECTIVA DA AVALIAÇÃO DE SISTEMAS DO ENSINO SUPERIOR}

De início, percebe-se que os modelos de avaliação de sistemas propostos por alguns autores tendem a valorizar e discutir informações quantificadas, ou seja, indicadores quantitativos, como nos trabalhos de Estrada (1999), Boclin (1999), Schwartzman (1997), Castro (2003a) e 
Gonzales (2003). Isso possivelmente ocorre, pois é difícil propor um modelo de avaliação nesse âmbito que abarque informações mais subjetivas, tendo em vista que um sistema de ensino caracteriza-se por sua amplitude e complexidade.

Kells (1996) discute a complexidade dos sistemas de ensino superior na América Latina, com vistas a propor um modelo de avaliação generalizado. De início, o autor afirma que os sistemas de avaliação do ensino superior na América Latina estão em fase "embrionária", ou seja, bastante incipientes, com mecanismos de avaliação pouco testados e desenvolvidos. A partir disso, para construir um modelo generalista aplicável à América Latina, Kells (1996) discorre acerca das características comuns aos sistemas de ensino superior desses países. Um dos pontos que destaca corresponde à heterogeneidade. Assim, um sistema de avaliação para tais países abarcará diversos tipos de instituições de ensino superior. Essa questão se refere não apenas aos diversos tipos de instituições (universidades, centros universitários, institutos, faculdades isoladas, etc.), mas também, segundo Kipnis e Burlamaqui (2004), às próprias diferenças regionais no que diz respeito, por exemplo, à economia.

Essa complexidade, constituída pela diferenciação e amplitude dos sistemas, pode ter implicações quanto à construção de um modelo de avaliação, até mesmo no que se refere à utilização de exames como o ENC. Pode-se inferir que sistematizar informações de cunho subjetivo e muito específico sobre instituições dificulte, por exemplo, a comparabilidade. Daí a proposição, predominante na literatura, de modelos de avaliação constituídos de indicadores quantitativos ou objetivos. Além disso, na discussão sobre a avaliação de sistemas, freqüentemente há a preocupação com a função reguladora da avaliação, que pode ter implicações sobre as discussões e definições de modelos de avaliação nesse âmbito. Martins (2005) argumenta:

A avaliação é um processo permanente de autoconsciência, tomada de posição, revisão, retomada ou redirecionamento de rumos institucionais e de programas e atividades. Tal processo, com certeza, é fundamento indispensável para a garantia $e$ a melhoria da qualidade. E seus resultados, obviamente, enriquecem e, até mesmo, dão sentido aos procedimentos de regulação. Tanto a auto-regulação, pelas próprias instituições que fazem a educação superior, como a regulação que compete ao Poder Público exercer. (p. 2) 
Belloni (1997), por sua vez, declara que a finalidade da avaliação de sistemas

... é a melhoria da qualidade e da eficiência do funcionamento do sistema como um todo, bem como o de cada instituição que o integra. Deve ser usada, também, para fins de credenciamento, isto é, para garantir que as instituições integrantes do sistema cumpram os requisitos mínimos para integrá-lo e para nele permanecer. (p. 27)

Nota-se, portanto, que a função de regulação do sistema pressupõe dificuldades no aprofundamento das realidades específicas das instituições, em suas subjetividades e processos, implicando a utilização de informações quantitativas ou mais objetivas.

Schwartzman (1997) observa que os modelos de indicadores quantitativos, propostos para a avaliação de sistemas, precisam ser desenvolvidos, pois, geralmente, as instituições têm fins bastante diferenciados e insumos heterogêneos que se combinam para produzir informações parciais e de qualidade pouco uniforme, controversas e com pouco poder de comparabilidade (essa questão será mais explorada no tópico 5, que trata da discussão dos indicadores).

\section{QUALIDADE/AVALIAÇÃO NA PERSPECTIVA DA AVALIAÇÃO INSTITUCIONAL}

Outra linha de discussão enfoca a avaliação institucional. Ou seja, alguns autores analisam instituições específicas e não o conjunto delas que compõem um sistema, entre eles: Belloni (1997), Sobrinho (1997), Leite e Morosini (1997), Gatti (1999), Amaral e Polidori (1999), Coêlho (2003), Newby (1999).

Em geral, observa-se que tal discussão, diferentemente do foco em sistemas, tende a valorizar informações mais subjetivas/qualitativas e o processo ocorrido no interior das instituições. Isso, possivelmente, pelo fato de que pensar a avaliação de um tipo determinado de instituição, como a universidade, permite maior aprofundamento em características específicas dessa realidade, ao contrário das possibilidades de um modelo pensado para um sistema de instituições. Nesse sentido, segundo Belloni (1997), a avaliação institucional tem como objeto a instituição em sua individualidade, isto é, está centrada nos processos e resultados das ações da instituição... (p. 26).

Schwartzman (1996) argumenta que as variáveis de processo podem ser abarcadas, sobretudo em avaliações como a institucional e a auto- 
avaliação. Para o autor, tais variáveis dizem respeito, por exemplo, aos métodos de ensino, à organização curricular e à gestão acadêmica. Belloni (1997) afirma que esse tipo de avaliação ...leva a decisões precipuamente internas à instituição, seus agentes, seus processos, sua estruturação (p. 26). Além disso, a autora considera que ele é, em si mesmo, processual, uma vez que ocorre de maneira contínua.

Outra característica refere-se à valorização de aspectos qualitativos, considerando a subjetividade presente nas instituições como um fator relevante. Nesse sentido, as interpretações que os sujeitos institucionais têm daquela realidade podem constituir informações relevantes. Sobrinho (1997) declara que a avaliação qualitativa abarca debates, negociações das divergências, a compreensão de que os fenômenos sociais comportam idéias, crenças, regras e normas que requerem interpretação e disputas. Por outro lado, para o autor, esse tipo de avaliação enfatiza as relações humanas, o modelo pedagógico, o clima institucional, a qualidade de vida, os processos institucionais e as relações de poder e saber. Coêlho (2003), por sua vez, ao criticar os modelos de avaliação que valorizam apenas "produtos da universidade", argumenta que a subjetividade precisa ser abarcada na avaliação, uma vez que os próprios sujeitos são historicamente determinados, sendo livres e respondendo de modos variados aos desafios e demandas que lhes são colocados.

Em geral, nota-se, com base na literatura levantada, que a avaliação institucional pode ter também uma ênfase interna e outra externa. A avaliação interna, segundo Sobrinho (1997), é realizada pelos agentes internos da instituição, comportando várias ações, como a sensibilização da comunidade e a definição de critérios e metodologias. Para Belloni (1997), os sujeitos internos são os alunos, professores e servidores técnicoadministrativos. Pode-se inferir que a avaliação interna corresponda à dimensão de auto-avaliação da instituição.

Já a avaliação externa, segundo Sobrinho (1997), envolve outros agentes normalmente membros da comunidade científica não pertencentes à instituição avaliada, reconhecidos pela sua competência técnica e ética. Para Belloni (1997), os sujeitos externos podem ser também empregadores, trabalhadores em geral e entidades sociais. Newby (1999) considera que esse tipo de avaliação pode ser realizado por pares, que são especialistas e/ou grupos de profissionais (peer review).

Algumas das características da avaliação institucional podem ser vislumbradas a partir do Programa de Avaliação Institucional das Universidades Brasileiras - Paiub, implementado em 1993 e apoiado pela Secretaria de Ensino Superior do Ministério da Educação - Sesu/MEC, que 
representa um exemplo claro de alguns mecanismos desse tipo de avaliação.

Para Leite e Morosini (1997), o objetivo principal do Paiub era ...rever e aperfeiçoar o projeto acadêmico e sociopolítico da instituição, promovendo a melhoria da qualidade e a pertinência das atividades desenvolvidas (p. 132). Segundo as autoras, a proposta previa as seguintes etapas: $1^{\mathrm{a}}$ ) Diagnóstico a partir de dados quantitativos existentes na instituição; $2^{\mathrm{a}}$ ) Avaliação interna - subdividindo-se em auto-avaliação, realizada pela comunidade acadêmica, e na consolidação dos dados, pela comissão de avaliação da instituição; $3^{a}$ ) Avaliação externa - realizada por acadêmicos de outras instituições, profissionais da área, representantes de entidades científicas, profissionais, empregadores, etc.; $4^{\mathrm{a}}$ ) Reavaliação interna - com base em todos os resultados avaliativos produzidos, propiciando uma análise com a comunidade acadêmica, $5^{\text {a }}$ ) Realimentação e difusão - que implica na reconsolidação dos dados, na tomada de decisões a implementar e na publicação dos resultados. Observam-se, com base nessas etapas propostas no Paiub, mecanismos de avaliação interna (inclusive, auto-avaliação) e externa (peer review).

Para Amaral e Polidori (1999), algumas características do Paiub acarretaram problemas. Como os membros da comissão avaliativa eram apontados pela própria instituição, a avaliação externa não foi independente, o que reduziu a credibilidade do processo. Ademais, segundo os autores, foi dada demasiada liberdade às instituições nas definições de seu próprio processo avaliativo, o que não garantiu a comparabilidade dos resultados obtidos entre diferentes instituições. Contudo, de acordo com Amaral e Polidori (1999), o principal problema deveu-se ao fato de que as instituições não tiveram incentivos suficientes para criar um sistema nacional efetivo. $O$ processo tornou-se demasiadamente lento, descentralizado e inconsistente, além do tempo ter sido insuficiente para a publicação da ampla quantidade de resultados.

A partir dessas colocações, nota-se que a avaliação institucional pode correr o risco de se tornar pouco eficaz, sobretudo se for somente caracterizada por mecanismos de avaliação interna e/ou auto-avaliação, estando sob responsabilidade dos sujeitos da própria instituição. Gatti (1999) atenta para essa questão quando afirma que os processos nessa modalidade avaliativa só adquirem possibilidade de impacto se considerados valiosos para a comunidade de referência, com participação efetiva. Por outro lado, infere-se que a não utilização de mecanismos externos, baseados em indicadores padronizados para as instituições, pode implicar na pouca comparabilidade de resultados de diferentes instituições. 


\section{QUALIDADE/AVALIAÇÃO NA PERSPECTIVA DA DISCUSSÃO SOBRE OS INDICADORES}

A discussão sobre a qualidade do ensino superior, necessariamente, perpassa a questão dos indicadores, como apontam Ferrer (1999) e Spagnolo (1999). Segundo Macrae (1985), para que uma variável seja considerada um indicador deve ser útil para a escolha de políticas públicas e/ou para a tomada de decisão. Para ele, isso implica saber como uma variável afeta um determinado valor final.

Remontando para a questão da avaliação da qualidade do ensino superior, uma variável ou estatística para ser útil deve influenciar um valor final relativo a esse nível de ensino. Nesse sentido, a questão relaciona-se à definição dessas variáveis de valor final. O desempenho dos cursos no ENC pode ser considerado uma variável de resultado e/ou valor final. Assim, por exemplo, a estatística relativa ao número de alunos/professor (variável 1), por si só, não tem relevância para inferências acerca de resultados de um curso. Contudo, se essa estatística expressa uma relação causal com a variável relativa ao desempenho de cursos em um exame (variável 2), passa a ter significação para a tomada de decisão nesse âmbito, pois as análises da relação entre essas variáveis tornaram possível inferir os níveis da primeira que afetam a segunda. Desse modo, um decisor de políticas poderia apontar em que quantidade o número de alunos/professor influencia negativamente o desempenho de um dado curso no exame (variável de resultado/valor final). Portanto, nessa visão para a construção de indicadores, inicialmente, é preciso que se tenha variáveis relativas à instituição ou curso que possam ser analisadas no que diz respeito à dependência com outras variáveis.

A visão de Castro (2003b) coincide com a de Macrae (1985). De acordo com a autora, para que sejam estabelecidos indicadores factíveis acerca de conteúdos, competências e habilidades, é necessário definir padrões mínimos relativos à infra-estrutura, gestão e oportunidades de aprendizagem, e também realizar estudos acerca da relação entre variáveis referentes a esses aspectos e uma variável dependente que se refere a um valor final. Assim, por exemplo, se a estatística relativa ao número de alunos/professor não prejudica, até certo ponto, o domínio de determinados conhecimentos e habilidades por alunos de um curso (variável relativa ao valor ou objetivo final), pode-se inferir que o número de alunos possa ser aumentado, tornando o curso mais eficiente (menos dispendioso) e efetivo (maior retorno à sociedade).

Spagnolo (1999), com relação à qualidade, expressa que é necessário saber em que medida os resultados pretendidos e obtidos se relacionam 
com os padrões aceitos, com definições explícitas e consensuais de exigências a serem cumpridas e de níveis a serem alcançados, concluindo, com base nessa colocação, que o problema dos standards é algo inevitável. Essa visão da necessidade de se estudar relações entre padrões estipulados e resultados obtidos/pretendidos demonstra uma concepção de indicadores aproximada à de Macrae (1985).

Outros autores, contudo, demonstram uma conceituação diferenciada sobre indicadores. Ferrer (1999), ao tratar da construção de indicadores de qualidade, propõe uma série de medidas/informações que podem ser utilizadas, como índices de qualificação de professores, índices de egressos e outros. Para ele, dada a complexidade da realidade avaliada, torna-se necessário recorrer a vários indicadores, buscando abarcar dimensões diferenciadas dessa mesma realidade. Todavia, o referido autor não utiliza o conceito de acordo com o sentido proposto por Macrae (1985).

Boclin (1999) também não utiliza (ao menos explicitamente) a conceituação de Macrae (1985) sobre indicadores. No entanto, percebe a mesma utilidade, expressando que um indicador deve ser relevante para a tomada de decisões.

Schwartzman (1996), ao abordar a metodologia para avaliação de cursos, propõe algumas informações que são tratadas como indicadores relacionados à qualidade; contudo, não discute a necessidade de se analisar como essas informações afetam um determinado valor final, como implica a conceituação de Macrae (1985).

\section{Alguns aspectos relacionados à utilização de indicadores}

Boclin (1999) afirma que a utilização de indicadores, dentre outras vantagens, ajuda a consolidar a "cultura de informação", permitindo correções imediatas e ajustes no processo de ensino-aprendizagem e em todos os seus envolvimentos. Para Randall (2002), uma das vantagens do uso de indicadores corresponde à possibilidade de tornar as informações sobre as instituições explícitas ao público em geral e, em especial, aos usuários do sistema.

Por outro lado, utilizar indicadores também pode causar alguns problemas, como uma certa "acomodação" das instituições. Segundo Newby (1999), a determinação de indicadores para avaliação pode ocasionar uma atitude de conformidade da instituição, na medida em que apenas precisam alcançar determinados padrões para receberem uma boa avaliação. Nesse sentido, de acordo com o autor ...qualidade não diz respeito a fazer o suficiente para alcançar um determinado padrão (...), mas, sim, fazer melhor do que antes (p. 265). Estrada (1999), por sua vez, argumenta que a utilização 
do termo "qualidade da educação" remete ao propósito de melhoramento. A avaliação representa a ferramenta metodológica, o juízo crítico e as propostas para essa melhora.

Kipnis e Burlamaqui (2004) argumentam que é preciso cuidado com a utilização de indicadores que sejam condicionantes, uma vez que as características e os potenciais das instituições são diferenciados; não se pode exigir necessariamente as mesmas coisas de cada uma delas. Para eles, devem-se evitar avaliações reducionistas (baseadas em poucos critérios e centralizadoras).

Outro problema diz respeito às informações que servem de base para o desenvolvimento de indicadores. Schwartzman (1997) considera que as que se referem ao sistema de ensino superior brasileiro ainda são bastante precárias. Em razão da pouca disponibilidade, e, sobretudo, da falta de organização das informações não é possível desenvolver indicadores confiáveis. Segundo o autor,

... os problemas metodológicos são inúmeros e devem-se à natureza peculiar da instituição universitária: fins múltiplos e insumos heterogêneos combinam-se para produzir informações parciais e de qualidade pouco uniforme, altamente controversas e com pouco poder de comparabilidade. (p. 174)

Não obstante, a utilização de indicadores, independentemente da conceituação que se tenha e dos possíveis problemas, é algo amplamente defendido por vários autores, como demonstrado no decorrer do texto. Geralmente, os autores defendem o uso de vários indicadores, simultaneamente, para a avaliação. Para Ferrer (1999), dada a complexidade inerente à realidade avaliada, na maioria das vezes não bastará apenas um indicador, mas vários. Desse modo, para ele faz mais sentido falar de sistemas de indicadores do que de indicadores isolados. Boclin (1999), na mesma direção, afirma que é mais adequado, para a avaliação, a utilização de indicadores múltiplos que possam ser relacionados.

\section{CONSIDERAÇÕES FINAIS}

A partir de abril de 2004, foi instituído o Sistema Nacional de Avaliação da Educação Superior - Sinaes. O novo sistema manteve algumas características do anterior, principalmente com relação à sua complexidade. Além do Exame Nacional do Desempenho dos Estudantes Enade, que substituiu o Exame Nacional de Cursos - ENC, o atual sistema 
é composto pela auto-avaliação institucional, pela avaliação institucional externa, pela avaliação das condições de ensino e instrumentos de informação (censo e cadastro), o que caracteriza, ao menos teoricamente, um sistema abrangente e adequado à noção de complexidade, debatida no âmbito da qualidade, conforme abordamos na discussão conceitual. Salientamos, contudo, ainda não haver disponibilidade de dados a respeito de como o sistema tem funcionado na prática.

O exame aplicado aos estudantes concluintes da graduação - Enade - avança em relação ao antigo, ao prever um teste de entrada aos alunos. Desse modo, tenta-se medir o valor adicionado ou agregado dos cursos à sua formação prévia, mensurado pelo exame de entrada, o que era uma das principais críticas ao extinto ENC, pois o desempenho dos alunos poderia estar associado não ao curso, mas à sua formação prévia, que freqüentemente está relacionada ao seu perfil socioeconômico. Burlamaqui (2004) constatou que tais variáveis tendem a estar associadas ao desempenho médio dos alunos em exames, como o ENC. Assim, entendemos que o controle de variáveis relativas ao perfil do alunado e ao seu conhecimento prévio (como, por exemplo, condições socioeconômicas e capital cultural) pode ser outra estratégia eficaz para minimizar o impacto da associação dessas variáveis sobre o desempenho de alunos concluintes em um exame, o que, de fato, aparece como um problema.

Outro método possível, talvez menos dispendioso que um exame de entrada, seria traçar um sistema de informação da entrada de alunos, baseado, por exemplo, na aplicação de um questionário sociocultural que permitiria levantar informações relativas, precisamente, ao seu perfil, quando do ingresso em determinado curso. A partir disso, na análise posterior dos resultados de um exame aplicado a concluintes de graduação, essas informações levantadas poderiam ser controladas. Outra alternativa seria desenvolver um exame de entrada integrado. O Exame Nacional do Ensino Médio - Enem - está sendo utilizado por algumas instituições como base de ingresso de seus alunos. Contudo, a adoção de um exame integrado, em nível nacional, poderia condicionar o sistema, minimizando características próprias de cada contexto regional.

Uma das críticas feitas aos exames diz respeito à sua possível utilização como único e/ou principal mecanismo avaliativo. Isso poderia significar um condicionamento das realidades avaliadas, que precisariam adequar-se às exigências do exame, focando seus processos de ensinoaprendizagem nessa direção. Entende-se que as instituições podem ter mecanismos e objetivos de aprendizagem próprios, pois cada região tem características sociais e econômicas diferentes que podem implicar nas definições da instituição. Além disso, há a questão de que a realidade está 
em constante transformação, sobretudo em um contexto de rápidas mudanças, como é a atual sociedade tecnológica.

Nota-se, contudo, que esta discussão teórica revela que alguns pontos presentes na literatura explicam o sentido da utilização de um exame como parte integrante de um sistema de avaliação para o ensino superior.

Uma vantagem com relação a exames corresponde à possibilidade organizativa do sistema. Os exames e informações levantadas, junto a alunos de todos os cursos de uma área, no país, permitem que se tenha informações, mesmo parciais, que possibilitam um panorama geral do sistema. Nesse sentido, é possível, por exemplo, identificar as instituições que têm, ao mesmo tempo, baixo desempenho em exames e a percepção negativa de seus alunos a respeito das condições de ensino e estrutura oferecidas. De todo modo, a associação dessas informações poderia gerar, facilmente, índices que ajudariam a apontar, mesmo com informações parciais, instituições com maiores problemas em relação a outras. A partir disso, outros dados, naturalmente, poderiam ser levantados e avaliados com o intuito de que a visão parcial inicial, proporcionada pelas informações do exame e de questionários, fosse complementada. Essa função organizativa pode ser considerada um aspecto relevante, sobretudo por tratar-se de sistemas amplos e heterogêneos, como é o caso brasileiro.

Outro ponto diz respeito à questão da eficácia. A qualidade, como salientam alguns autores citados, é freqüentemente abordada com base nesse enfoque. Outros autores, embora não utilizem diretamente o termo, declaram que os objetivos da instituição ou do curso devem ser constantemente revistos e alcançados.

A dimensão da eficiência de um curso ou de uma instituição, por sua vez, também acaba perpassando a questão dos objetivos. Assim, a adequação dos gastos é analisada em relação ao alcance de metas ou objetivos. Tanto com relação à eficiência quanto à eficácia, a pergunta que surge é a seguinte: uma instituição é eficiente e/ou eficaz com relação ao alcance de que objetivos?

Outros autores, como visto, apontam a necessidade de se trabalhar com medidas relativas ao produto/resultado de uma instituição ou ao seu desempenho com relação a algum parâmetro. A conceituação de Macrae (1985) sobre indicadores implica, ainda, que se desenvolvam medidas relativas ao valor final e/ou aos resultados, que possam ser analisados com relação à dependência de outras variáveis, em relações causais.

Infere-se da discussão, portanto, que é difícil pensar em um sistema de avaliação que não tenha alguma medida de resultado, relativa ao alcance de objetivos, que sirva de base para a análise e para uma maior 
racionalidade na tomada de decisões. Considerando que, em instituições educacionais, os principais objetivos, provavelmente, se referem ao ensino que são capazes de promover, entende-se que, em razão disso, decorre a questão sobre o quê, efetivamente, foi apreendido por um estudante ou adicionado à sua formação. Embora um exame como o Enade não mostre, necessariamente, o que foi acrescentado à formação dos alunos, pode revelar determinados conhecimentos e habilidades que eles possuem ao final de um curso de graduação. Assim, de todo modo, seus resultados podem relacionar-se aos objetivos de um curso. O perigo, contudo, está no peso excessivo dado ao exame, que pode condicionar a realidade, eliminando particularidades e potencialidades de cada contexto e região.

Nessa direção e em uma perspectiva que considera a complexidade das realidades avaliadas, seja no âmbito de sistemas ou, especificamente, de instituições ou cursos, avaliar e regular o ensino superior de graduação, com base no peso de um indicador isolado, corresponderia a uma ação reducionista que deixaria de considerar outros possíveis elementos relevantes, de ordem qualitativa e quantitativa, relativos aos resultados e processos, importantes para o conhecimento do sistema e a tomada de decisão. A complexidade das realidades avaliadas, nesse sentido, implica um sistema de avaliação também complexo, constituído de tipos diferenciados de variáveis, que possam ser analisados em sua relação e permitir um conhecimento aprofundado do sistema, em suas várias dimensões. Pressupõe-se que isso poderia auxiliar nos processos de tomada de decisão.

Portanto, pelo que foi discutido teoricamente, um sistema complexo e integrado de avaliação, baseado em diversos tipos de informações que permitam o conhecimento aprofundado do sistema de ensino superior, parece a direção mais adequada. $\mathrm{O}$ sistema atual do MEC se adequa a essa perspectiva, porém há outros pontos a serem considerados.

As variáveis/indicadores tradicionais podem ser utilizados, mas, para além deles, a discussão teórica demonstrou que há outras informações, por exemplo, de natureza qualitativa, regionais e relativas a processos, que podem ser úteis para o conhecimento do sistema e tomada de decisão. Como exemplo, pode-se citar, dentre outros aspectos: a análise de linhas de pensamento e valores institucionais (cultura institucional); do clima institucional; do comprometimento; da resistência a mudanças; da satisfação acadêmica; da integração acadêmica; de mecanismos de tomada de decisão e das potencialidades econômicas regionais. Nota-se que esses e outros aspectos, embora, a princípio, de cunho mais subjetivo, podem fomentar informações quantitativas com a criação de índices, como, por exemplo, de integração acadêmica e, mesmo, relativos à predominância de 
determinados valores culturais, que podem ser úteis para a análise de um contexto institucional e tomada de decisão. Isso poderia minimizar a problemática da pouca comparabilidade e dificuldade quanto à organização de informações mais subjetivas.

Por fim, retomamos Belloni (1997) que explica que a avaliação visa, dentre outros aspectos, identificar problemas e possibilitar sua correção. No entanto, os erros precisam ser corrigidos rapidamente. Nessa perspectiva, não basta apenas que se tenha um sistema complexo de avaliação, fundamentado em diversos indicadores, que considere, inclusive, particularidades regionais. Torna-se necessário um método objetivo, baseado em informações que possam ser levantadas com agilidade. Nisso, temos muito no que avançar. Desse modo, a internet, como rede interligada de dados, poderia ser usada para captar e sistematizar informações. Contudo, a utilização desses recursos, como ferramentas úteis para a avaliação, implicaria pesquisas e vontade política dos decisores, nos âmbitos do sistema e das instituições.

\section{REFERÊNCIAS BIBLIOGRÁFICAS}

AMARAL, A.; POLIDORI, M. Quality evaluation in Brazil: a competency based approach? Higher Education Policy. Grand Britain: Elsevier Science, n.12, p. 177-199, 1999.

BELLONI, I. A Universidade e o compromisso com a avaliação institucional na reconstrução do espaço social. In: COSTA, M. J. J. (org.) Avaliação institucional: desafio da universidade diante de um novo século. Belém: EFPA, p. 17-34, 1997.

BOCLIN, R. Indicadores de desempenho: novas estratégias da educação superior. Ensaio: avaliação e políticas públicas em educação. Rio de Janeiro: Fundação Cesgranrio, v. 7, n. 24, p. 299-308, jul./set. 1999.

BRASIL. Lei n. 10.861, de 14 de abril de 2004: Institui o Sistema Nacional de Avaliação da Educação Superior (Sinaes) e dá outras providências.

Portaria MEC n. 20.051, de 9 de julho de 2004: Regulamenta os procedimentos de Avaliação do Sistema Nacional de Avaliação da Educação Superior (Sinaes). 
BURLAMAQUI, M. G. B. Qualidade no ensino superior: um estudo sobre a influência de determinados fatores no Exame Nacional de Cursos. Brasília, DF, 2004. Dissertação (mestr.). Universidade de Brasília.

CASTRO, M. H. G. O Novo debate sobre o uso de padrões na educação. Disponível em: <http://www.inep.gov.br> Acesso em: 25 ago. 2003 .

. Education assessment and information systems in Brazil. Disponível em: <http:/ / www.inep.gov.br> Acesso em: 25 ago. 2003b.

COÊLHO, I. M. Educação superior: por uma outra avaliação. In: DOURADO, L. F.; CATANI, A. M.; OLIVEIRA, J. F. de (orgs.) Políticas e gestão da educação superior: transformações recentes e debates atuais. São Paulo: Xamã; Goiânia: Alternativa, 2003.

COHEN, E.; FRANCO, R. Avaliação de projetos sociais. Petrópolis: Vozes, 1993.

CUNHA, C.; WERTHEIN, J. Políticas de educação: idéias e ações. Brasília: Unesco, 2001 (Cadernos Unesco Brasil. Série educação, 5).

ESTRADA, L. R. G. Hacia un modelo de evaluación de la calidad de instituciones de educación superior. Revista Iberoamericana de Educación. OEI, n. 21, set./dez. 1999.

FERRER, A. T. La Evaluación y la calidad: dos cuestiones sometidas a discusión. Ensaio: avaliação e políticas públicas em educação. Rio de Janeiro: Fundação Cesgranrio, v. 7, n. 22, p. 25-46, jan./mar. 1999.

GATTI, B. A. Ensino superior e avaliação institucional: um modelo em implantação. Revista Brasileira de Estudos Pedagógicos. Brasília: Inep, v. 80, n.194, p. 148-155, jan./abr. 1999.

GONZALES, E. J. Evaluation systems in Latin America. Disponível em: <http://www.inep.gov.br> Acesso em: 25 ago. 2003.

KELLS, H. R. Higher education evaluation systems for Latin America: an analysis of recent experiences and the formulation of a generalized model. Higher Education Policy. Grand Britain: Elsevier Science, v. 9, n. 3, p. 239-256, 1996. 
KIPNIS, B.; BURLAMAQUI, M. G. B. Heterogeneidade das universidades públicas federais: implicações para o processo decisório. In: Encontro de Pesquisa em Educação da Região Centro-Oeste - EPECO, 7. Anais do... Goiânia: EFG/ECG, 2004.

LAPA, S. J.; NEIVA, C. C. Avaliação em educação: comentários sobre desempenho e qualidade. Ensaio: avaliação e políticas públicas em educação. Rio de Janeiro: Fundação Cesgranrio, v. 4, n. 12, p. 213-236, jul./set. 1996.

LEITE, D. B. C.; MOROSINI, M. C. Avaliação institucional como um organizador qualificado: na prática, é possível repensar a universidade? In: SGUISSARDI, V. (org.) Avaliação universitária em questão: reformas do Estado e da educação superior. Campinas: Autores Associados, 1997. p. 123-148.

MACRAE JR., D. Policy indicators: links between social science and public debate. Chapel Hill: The University of North Carolina Press, 1985.

MARTINS, R. C. R. Novos encontros, novas sínteses. In: XIMENES, Daniel de Aquino (org.) Avaliação e regulação da educação superior: experiências e desafios. Brasília: Funadesp, 2005, p. 41-66.

MOROSINI, M. Avaliação institucional e qualidade universitária. In: COSTA, M. J. J. (org.) Avaliação institucional: desafio da universidade diante de um novo século. Belém: EFPA, 1997. p. 141-153.

NEWBY, P. Culture and quality in higher education. Higher Education Policy. Pergamon, n.12, p. 261-275, 1999.

NUNES, E. Futuros possíveis, passados indesejáveis. Rio de Janeiro: Garamond, 2001.

RANDALL, J. Quality assurance: meeting the needs of the user. Higher Education Quaterly. USA: Blackwell Publishers, v. 56, n. 2, p. 188-203, abr. 2002.

Seminário Avaliação da Educação Superior: a experiência do Reino Unido e do Brasil em debate. Brasília: Inep, 2001. 
SAMPAIO, H.; LIMONGI, F.; TORRES, H. Eqüidade e heterogeneidade no ensino superior brasileiro. Brasília: Inep, 2000.

SCHWARTZMAN, J. Uma metodologia de avaliação de cursos de graduação. Ensaio: avaliação e políticas públicas em educação. Rio de Janeiro: Fundação Cesgranrio, v. 4, n.12, p. 237-264, jul./ set. 1996.

. Um sistema de indicadores para as universidades brasileiras. In: SGUISSARDI, V. (org.) Avaliação universitária em questão: reformas do Estado e da educação superior. Campinas: Autores Associados, 1997, p. 123-148.

SPAGNOLO, F. O Sistema britânico de garantia de qualidade do ensino superior: lições para o Brasil. Revista Brasileira de Estudos Pedagógicos. Brasília: Inep, v. 80, n. 196, p. 508-526, set./dez. 1999.

SILVA, J. C. O Exame Nacional de Cursos: a utilização de resultados por instituições do Distrito Federal. Brasília, 2001. Dissertação (mestr.) Universidade de Brasília. $155 \mathrm{f}$.

SOBRINHO, J. D. Avaliação da educação superior. Petrópolis: Vozes, 2000.

Avaliação institucional e qualidade universitária. In: COSTA, M. J. J. (org.) Avaliação institucional: desafio da universidade diante de um novo século. Belém: EFPA, 1997. p. 35-54.

Recebido em: maio 2007

Aprovado para publicação em: setembro 2007 
